\title{
ACTIVE-LEARNING METHODS TO IMPROVE STUDENT PERFORMANCE AND SCIENTIFIC INTEREST IN A LARGE INTRODUCTORY OCEANOGRAPHY COURSE
}

\author{
Richard F. Yuretich Department of Geosciences, University of Massachusetts, Amherst, MA 01003, yuretich@geo.umass.edu \\ Samia A. Khan \\ School of Education, University of Massachusetts, Amherst MA, 01003, sakhan@educ.umass.edu \\ R. Mark Leckie \\ Department of Geosciences, University of Massachusetts, Amherst, MA 01003, mlechie@geo.umass.edu
} John J. Clement

School of Education and Scientific Reasoning Institute, University of Massachusetts, Amherst, MA 01003 , clement@educ.umass.edu

\section{ABSTRACT}

Teaching methods that are often recommended to improve the learning environment in college science courses include cooperative learning, adding inquiry-based activities to traditional lectures, and engaging students in projects or investigations. Two questions often surround these efforts: 1) can these methods be used in large classes; and 2) how do we know that they are increasing student learning? At the University of Massachusetts, we have transformed the environment of a large-enrollment oceanography course (600 students) by modifying lectures to include cooperative learning via interactive in-class exercises and directed discussion. Assessments were redesigned as "two-stage" exams with a significant collaborative component. Results of student surveys, course evaluations, and exam performance demonstrate that learning of the subject under these conditions has improved. Student achievement shows measurable and statistically significant increases in information recall, analytical skills, and quantitative reasoning. There is evidence from both student surveys and student interview comments that for the majority of students, the course increased their interest in science - a difficult effect to achieve with this population.

Keywords: oceanography; education - undergraduate; education - active learning; evaluation

\section{INTRODUCTION}

The presumably dreary state of teaching in many science courses at the college level has been laid out in a variety of publications, ranging from government documents and official studies to journal articles and books. The general consensus of these analyses is that many science courses, especially those at the introductory level, are "dry as dust." Courses often fail to project the excitement and discovery experienced by scientific researchers. There are, however, many efforts currently underway to improve this situation. The National Science Education Standards recommend several teaching strategies at the K-12 levels including inquiry-based teaching, guiding and facilitating learning, engaging in ongoing assessment, managing learning environments, and establishing a community of science learners. Several of these methods, such as cooperative learning and teaching by inquiry, are now making inroads into the higher education community. The overall goal is to have science taught as it is practiced, through in- vestigation, discovery and guided analysis. Most of these strategies are easily adapted to the relatively small classes at liberal-arts colleges or in courses designed for science majors. Can these techniques be used successfully in large-enrollment introductory courses for the general students such as those commonly found in many public colleges and universities?

Cooperative learning has shown real promise in helping students learn science, mathematics and engineering. Statistically significant improvements in academic achievement, student attitudes about learning, and persistence in taking science-related courses have been reported based on analysis of dozens of trials . By working in groups, students can help each other understand basic concepts and formulate more realistic solutions to complicated problems. However, not all "group work" is successful. Groups working together on long-term investigations need good structure to be effective, a task that is more easily accomplished in small classes, especially those with laboratory or field components. In an ideal world, all classes would be designed to take advantage of these advances in educational research. However, in many universities and colleges introductory courses in the sciences (including the geosciences) are often conducted in large auditoriums or lecture halls, where the instructor is commonly separated from the students by an imposing podium, or even a stage. Chairs are bolted securely to the floor, and access to the students is limited to a pair of aisles running the length of the auditorium. How can these classes benefit from the positive dynamics of group interaction when the room itself is so instructor-centered? In large classes, using informal groups that work on short investigations is the only viable option. However, questions or topics must be still be structured effectively to take advantage of the discussions that can occur in a collaborative format.

Rethinking the way college science and mathematics are taught has been one of the principal goals of STEMTEC (Science, Technology, Engineering and Mathematics Teacher Education Collaborative), an NSF Collaborative for Excellence in Teacher Preparation with headquarters in western Massachusetts. As of August, 2000, 150 college faculty members from 20 higher- education institutions ranging from community colleges through a "Research 1" university, have been introduced to the recommended pedagogy of the National Science Education Standards. These faculty members, working with a group of superior K-12 faculty, have been challenged to redesign their courses to make them more student-centered by incorporating cooperative learning, 
inquiry, alternative assessment strategies and opportunities for teaching by students. Although the ultimate goal of the STEMTEC initiative is to prepare more and better K-12 science and math teachers, these instructional methods are designed to raise the level of scientific discourse for all enrolled students and improve the quality of the learning environment.

Oceanography at UMass-Amherst - In the Geosciences, GEO 103, Introductory Oceanography, has been at the forefront of the STEMTEC course redesign process. This course has a long history as the one with the largest enrollment in Geosciences at the University of Massachusetts, averaging more than 1200 students each academic year. During the decade of the 1980's, the course evolved into a model of presumed administrative and instructional efficiency. A single instructor teaches two sections, each with $300+$ students, with the sections scheduled back-to-back. The classes meet twice a week for 75 minutes, and there are no discussion or laboratory components, since there are only two teaching assistants to help with the course. Students receive their grades almost exclusively on the basis of multiple-choice examinations, dictated by the need for machine scoring of the results.

In spite of this seemingly unfriendly environment, the course has maintained its popularity over the years. It appeared that the only limiting factor on enrollment was the size of the auditorium. One contributing factor to the popularity may have been the consistency in the teaching of the course. There are four regular instructors who rotate the teaching responsibility; on average, each instructor will teach the class once every two years. All the instructors have collaborated in acquiring resources, sharing ideas and management strategies, adopting textbooks and maintaining a working library of slides, videos and other supporting materials. Although teaching styles differ, all the instructors regularly received ratings of "effective" to "very effective" on the end-of-semester student course evaluations.

Yet something was still wrong. Despite our best efforts to deliver coherent, enthusiastic and well-illustrated lectures, we questioned whether many students were learning as much as they could. Attendance on a typical day hovered at or below $50 \%$, except just before exams when the class was packed. Students would routinely leave early or arrive late. Our attempts to engage the class in questioning and discussion resulted in the animated participation of a small cadre of motivated students, but the rest of the class was listless and disinterested. Pockets of students in the back corners would often have their own discussion groups in progress during the lecture, with the topic of these conversations unrelated to anything scientific or academic. The best solution to the problem would be to make the class smaller and introduce a laboratory component, but this was not possible given the available resources. We tried several ad hoc techniques to improve the learning environment, some with more apparent effect than others. One successful change involved dividing the class meeting into shorter segments and varying the instructional mode during each segment . For example, 15 minutes of lecture is followed by a short video. Discussion of the video serves as another segment, and this provides a segue into a closing mini-lecture. Another fruitful technique involved using a "question box" so students could jot down questions that they could not ask during class time. These questions are addressed at the opening of the next class, or they serve as a springboard for discussion. Eventually, we introduced a few short in-class assignments and homework problems to help in sharpening the students' quantitative and deductive reasoning. These provided additional information for student assessment other than the multiple-choice tests. Lastly, we took a page from our colleagues in physics and chemistry and developed a few demonstrations to illustrate basic principles, such as isostasy or salinity. Student interest picked up, especially when the demonstration served to focus class discussions or follow a line of questions. It was clear that we were on the right track, but our approach to change needed to be more systematic and comprehensive, and we also needed to have some way of evaluating the impact of these changes on student learning.

The STEMTEC Course Re-Design Program - It was at this juncture that the STEMTEC project began. We spent two weeks during the summer of 1997 discussing issues of teaching and learning with college and K-12 geoscience faculty within the collaborative. We quickly recognized that improving science and math education for all undergraduates was a key element in reaching prospective K-12 teachers. With such a large enrollment, the oceanography course is a cornerstone of this endeavor. The STEMTEC program emphasized three major teaching strategies: cooperative learning, learning through inquiry, and alternative assessment of student performance. During the following academic year, the two authors who are also course instructors (RFY and RML) introduced these techniques, made changes based on our experiences and evaluated the results during a follow-up summer institute. The two remaining authors (SAK and JJC) served as evaluators. We sat among the students and observed several classes. Subsequently, we videotaped several of the new teaching techniques, using microphones to capture the dialogue between student volunteers. Data were also obtained from a focus group of paid volunteers who met at the end of the semester. Students were asked to give written responses to questions followed by a discussion of the questions. Additional questions were added to the standard end-of-semester course evaluation to gauge the specific impact of the changes on student learning and attitudes.

Interactive In-class Exercises - The general goals for the oceanography course are: to give the students a taste of the scientific discovery process; to increase their skills in problem solving and deductive reasoning, to give them the opportunity to uncover knowledge they already have, and to have them discover more about the world around them and the systems that regulate it. Our first effort to meet these goals was to increase the number of in-class exercises to be a regular feature of almost every class. The exercises are designed to help students think like scientific investigators. We have developed over 35 of these activi- 


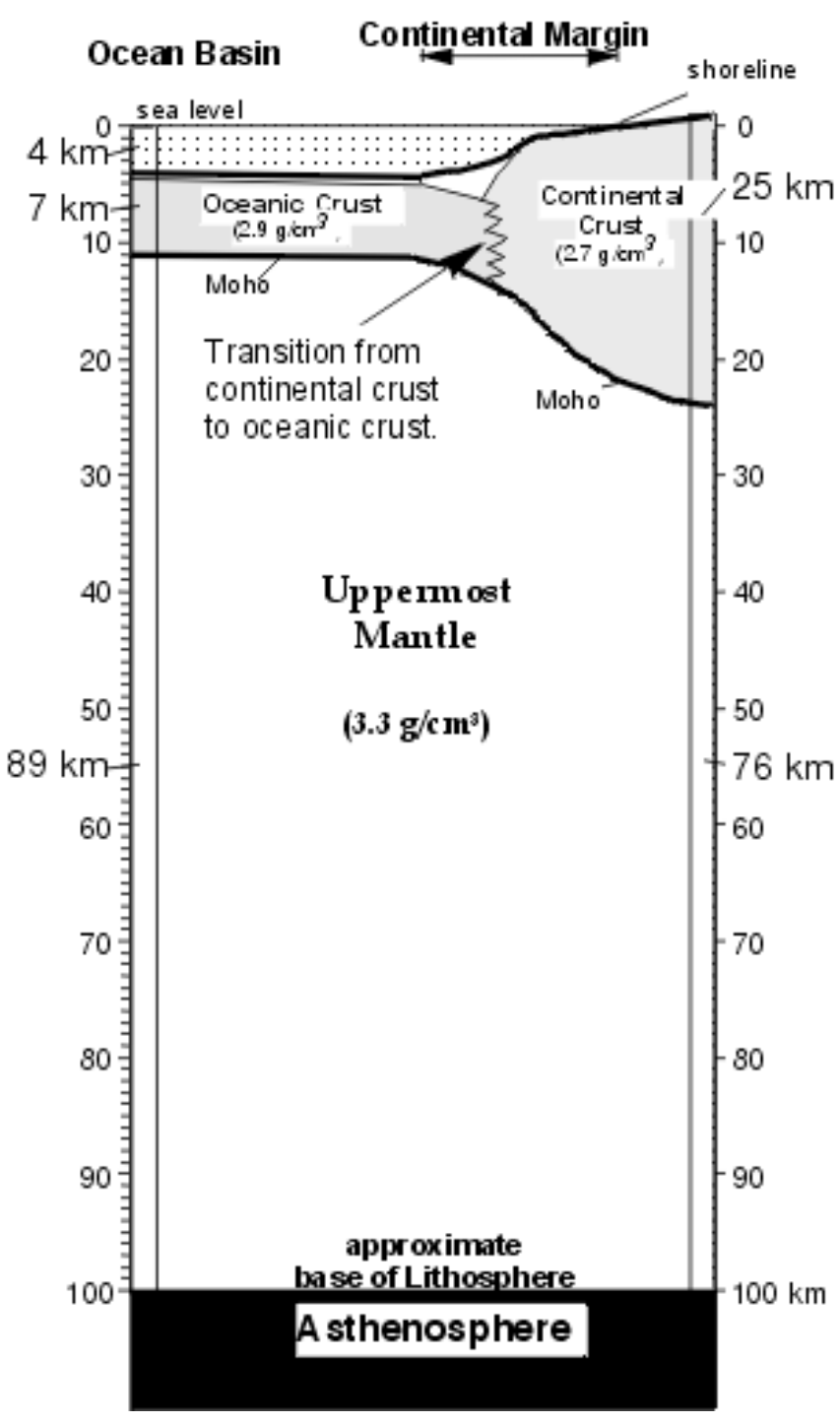

Figure 1. An example of an interpretation and calculation exercise done in class. Students ponder the questions on their own ("think"), then will write out answers based on discussions with their immediate neighbors ("pair"). This is taken from Exercise 4, Isostasy, in Leckie and Yuretich (2000).

ties that span all topics in oceanography, which are now available in book form (Leckie and Yuretich, 2000). The exercises involve interpreting diagrams and performing calculations (Figure 1), synthesizing concepts and developing principles (Figure 2), and working with scientific data (Figure 3). Questions are often posed around segments of short videos to provide a basis for discussion of the most significant or controversial points. Writing is an important component of the answers to these questions.

The exercises are done in informal groups, generally using the method of "think-pair-share." The students are given a question to ponder, and they write their initial thoughts or preliminary calculations on a reporting sheet. These reporting sheets help pose the questions and guide the students in their thinking. Next, they discuss their
1) What is density? List some ways that you could measure the density of water.

2)Is salt water more or less dense than fresh water? How could you tell?

3) Design an experiment that would allow you to measure the change in the density of water as temerpature changes.

4) Your instructor may show you some experiments about measuring the density of water. Report the results.

Figure 2. An example of an in-class exercise emphasizing understanding of fundamental principles. Condensed from Exercise 12, Density, in Leckie and Yuretich (2000).

ideas with their immediate neighbors, and they can amplify or modify their first answers as appropriate. The last step is to review the responses with the entire class and synthesize some general observations and conclusions. The response sheets are collected at the end of class and are reviewed for completeness and comprehension. Sometimes they reveal common misconceptions or difficulties, which can benefit from further discussion or explanation in subsequent classes. We assess these in-class activities using a simple rubric with a 3-point scale, and the result forms part of the students' grade. The completed sheets are made available to the students after they have been reviewed. Although these are completed as group tasks, the exercises are assessed individually. Some of the more extensive activities can be continued or assigned as homework to complete, but most exercises can be finished in 20 to 30 minutes. They achieve two of the goals of the STEMTEC program: to use group activities and inquiry to enhance student learning.

Two-stage Cooperative Exams - Another new component is the two-stage cooperative exam. This is based loosely on the technique of the "pyramid exam" used in calculus classes at Smith College, whereby students take the same exam repeatedly during an extended period of time but in different settings: individually, working in pairs, and in larger groups. The goal here is to turn the exam into a learning experience, so that the students can work out reasonably complicated problems and understand the process of their reasoning. In a very large class, such an elaborate structure is not possible, but we have achieved the same effects by modifying traditional multiple-choice exams. During the first 30 minutes of the class period, the students take a shorter version of the multiple-choice exam (20 to 25 questions) in the usual manner, and they hand in their answer sheets at the end of that time. We issue them new answer sheets, and they take the exam a second time during the remainder of the class (usually 45 minutes), this time with collaboration encouraged. Students are also allowed to use books, notes and any other resources they have to answer the questions. To make the exam more challenging, we also add several extra questions to be answered as part of the collaborative part of the exam. These questions are designed to require more thought, calculation, or interpretation, and a correct answer is more easily reached after discussion in a group. 


\begin{tabular}{|c|c|c|c|c|c|c|}
\hline \multicolumn{7}{|c|}{ Here are data from an experiment in measuring productivity: } \\
\hline Depth (m) & $\begin{array}{c}1 \\
\begin{array}{c}\text { O2 at start } \\
(\mathrm{ml} / \mathrm{l})\end{array} \\
\end{array}$ & $\begin{array}{c}2 \\
\mathrm{O} 2 \text { in dark } \\
\text { bottle }(\mathrm{ml} / \mathrm{l})\end{array}$ & $\begin{array}{c}3 \\
\mathrm{O} 2 \text { in clear } \\
\text { bottle }(\mathrm{ml} / \mathrm{l})\end{array}$ & $\mathbf{R}$ & NP & GP \\
\hline 0 & 6.0 & 3.8 & 8.8 & & & \\
\hline 10 & 6.0 & 3.9 & 9.0 & & & \\
\hline 20 & 6.0 & 4.0 & 9.5 & & & \\
\hline 30 & 6.0 & 4.0 & 10.0 & & & \\
\hline 40 & 6.0 & 4.1 & 8.6 & & & \\
\hline 50 & 6.0 & 4.3 & 7.6 & & & \\
\hline 60 & 6.0 & 4.4 & 6.8 & & & \\
\hline 70 & 6.0 & 4.7 & 6.3 & & & \\
\hline 80 & 6.0 & 4.9 & 5.8 & & & \\
\hline 90 & 6.0 & 5.1 & 5.5 & & & \\
\hline 100 & 6.0 & 5.3 & 5.3 & & & \\
\hline
\end{tabular}

1) How can we determine the respiration $(R)$ ?

the net propuctivity $(\mathrm{NP})$ ?

the gross productivity $(\mathrm{GP})$ ?

2) Plot these values from the table on a graph of $\mathrm{O} 2$ versus depth.

3) Indicate on the graph, the oxygen compensation level and the bottom of the photic zone. See pages 152-153 for more information.

Figure 3. An example of an exercise involoving the analysis of scientific data. Taken from Exercise 24, Productivity, in Leckie and Yuretich (2000).

These latter questions are often based upon problems that were part of the in-class exercises. The students' grades are a weighted average of the individual and the collaborative components. In order to encourage collaboration and open discussion during the cooperative phase of the exam, we do not count the second part of the exam if it lowers a student's grade. This simple change in exam format motivates the students to discuss the reasons for their answers energetically with their neighbors. They are implementing active learning during the exam and are forced to practice aspects of critical thinking as they discuss the reasons behind their answers to the questions. We have also increased the number of exams slightly (by one) in order to reduce the propensity for last minute "cramming" and to give a thorough exam in a shorter time frame.

\section{RESULTS}

Attendance and Engagement - We have compiled several lines of evidence to support the success of our strategies in our oceanography class. Attendance has improved markedly. In contrast to our previous experience of half-empty (or worse) lecture halls, attendance during class now averages nearly $80 \%$ (Figure 4 ). These data were compiled from the number of exercises that were completed and handed in during class. The results should not be surprising, given that there is now an incentive to come to class. Although we would like to think that this is an intellectual incentive, there is also strong practical motivation given that missed exercises will have a negative impact upon the student's final grade. Students will not learn in the classroom if they are not there! Interviews of students confirm this assessment. One observed that "more people show up for that class than any other of my lectures...this class has the most attendance." Another remarked that "attendance is important to learning." The value of the in-class discussions and exercises was summarized by another student: " ...you're taking your knowledge and you are applying it to something, so that helps you a lot on the exams, to better understand." These examples illustrate that cooperative learning and problem solving can work even in a large lecture. 


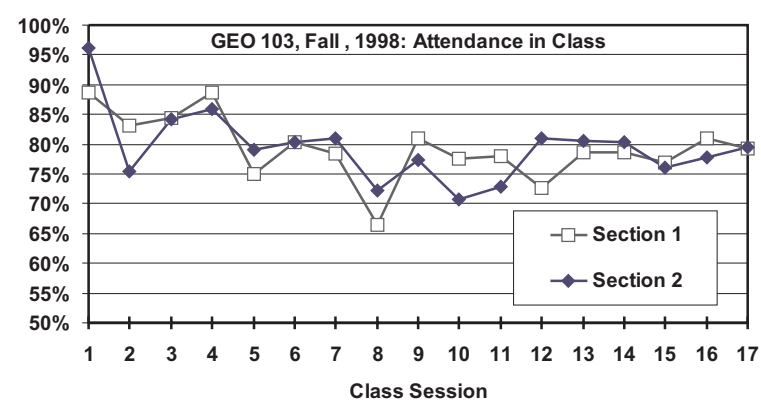

Figure 4. Class attendance in GEO 103, Introductory Oceanography during the Fall, 1998 semester averaged $80 \%$ Attendance during previous semesters averaged close to $50 \%$.

There is also a much greater engagement of a larger population of students during class time. This cannot be quantified in the same way as simple attendance, but systematic observations by instructors and teaching assistants show that late arrivals and early departures are reduced substantially. We have again provided an incentive, since in-class exercises frequently start at the beginning of the class but they are not turned in until the students exit the auditorium. We keep alphabetized file boxes at the front of the room behind the podium so that students must come forward to turn in their sheets and this discourages all but the most brazen from slipping out early. We never accept late exercises.

More importantly, the students are engaged intellectually during the class. As they work on the exercises, instructors and teaching assistants traverse the room and listen in on the discussions. Although there are some silent groups, most are involved in an animated debate about the questions or calculations in the assignment. The observations of the class confirmed that more than $85 \%$ of the students turned to face their neighbors and began talking and writing in the first minute of an exercise including those who sat in the back row, the traditional hangout for marginal participants. Our monitoring of the discussions confirmed that the talking centered around the subject; only if the exercise went on too long did groups digress onto weekend plans, clothing and the other many distractions of student life. These provide a useful indicator to begin the "sharing" phase of the discussion.

Improvements in Exam Results - A concern expressed by many instructors is that cooperative learning limits their ability to cover content. However, we have not measured any major differences in the overall abilities of the students' performance on traditional tests in the subject area. We compared the exam scores (using only the solo parts of the exams from 1998) for the last three times that the course was taught by one of us (RFY). Table 1 shows that there is a small gain in the average scores on the exams in the redesigned version of the course. Using Student's t-test, these increases are significant at the $99 \%$ level

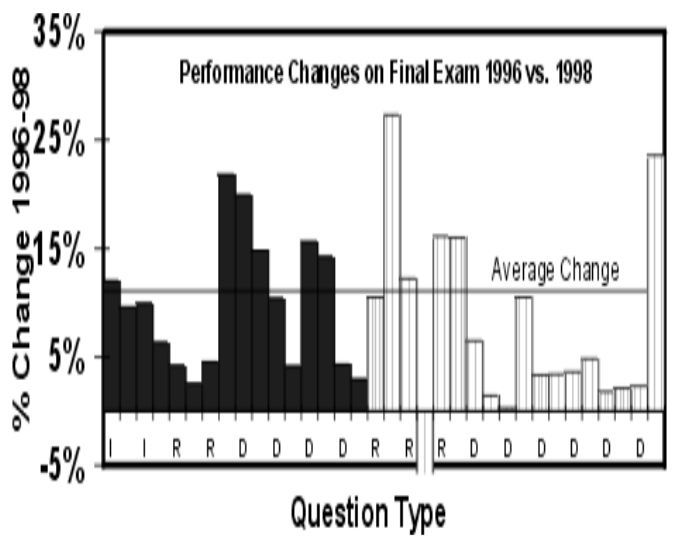

Figure 5. Comparison of student answers to identical or similar questions on final exams. Vertical axis represents the percent increase (or decrease) in the number of students who answered the question correctly in the latter year. Black bars are questions from last $20 \%$ of course; gray bars are questions from previous $80 \%$ of course. " $I$ " = interpretive questions, where students had to analyze graphs or diagrams; " $R$ " = factual recall questions; " $D$ " = deductive reasoning questions; " $C$ " = questions involving numerical calculations.

or better, owing to the large sample size. The consistent standard deviation for the exams also shows the relative stability and the size of the student population in the course.

Noteworthy is the large improvement in the final exam: it is the highest numerical score of any exam during the 3 iterations of the course. This is arguably the most consistent comparator of all the exams because the in-class tests were repackaged differently from preceding years. We compared the final exams from Fall 1998 and Spring 1996 more rigorously. The same instructor (RFY) taught both of these semesters, but the 1998 version incorporated the full spectrum of interactive and collaborative methods into the class. The final exam was crafted deliberately to include a substantial number of questions that were either identical or similar to those from the previous iteration. The average score on this exam was substantially higher in 1998 than in 1996 (Table 1). In addition, of the 38 questions that were exactly or nearly the same between the two exams, the students in the redesigned course did better on 37 of them, and in some cases the results were markedly higher (Figure 5). These questions comprised several categories: factual recall, calculations, interpretation and deduction. The questions also spanned topics from the beginning of the semester to those discussed in class most recently. The most recent class performed noticeably better in all categories. Although their margin of improvement for the last segment of the course is higher, they also demonstrate a much better recall of information from earlier topics. We conclude that the active engagement of the students in the learning process together with their increased attendance in class was the principal cause of this improvement.

Effects of Cooperative Exams - The cooperative exam format increased the value of the exams as a learning experience. As one student commented: "You can't get away with not studying... because the solo part of the exam counts for 

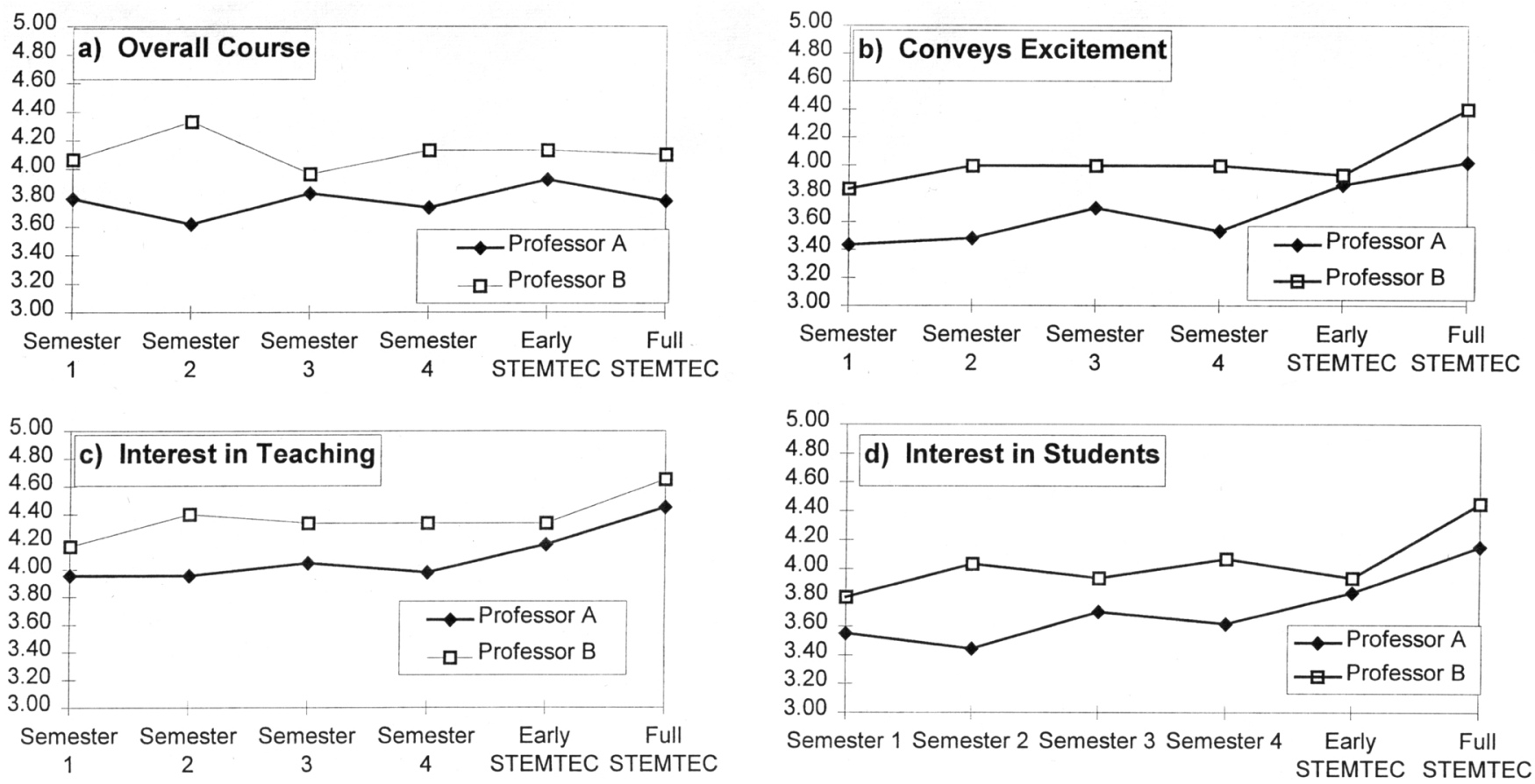

Figure 6. Scores taken from the summative evaluations for oceanography when taught by the authors. "Early STEMTEC" marks the introduction of some in-class activities; "Full STEMTEC" incorporates all components mentioned in this article.

$75 \%$ of the overall grade, which is a huge part... the group part really doesn't make that much of a difference." In preparation for the exam, one student indicated that he studied less, another just as much, while two students indicated that they studied more for "these kinds of exams than 'regular ones.'" In one case, studying involved simulating the group process of the exam in the home: "I study with...5 other people... we get in a big group and discuss it because we're going to be doing that in class anyway, and I benefit from that."

Some students entered the lecture theater in cooperative "teams" and geographically positioned themselves so that interaction was effective. This team strategy reflects some understanding of the physical nature of cooperative group work. Students attempted to arrive at the best possible answers as they reviewed the same exam questions again and answered a few new questions as well. Within this discussion, several strategies for changing answers from the solo part to the group part evolved. Students stated that they will change their answer on the group part of the exam "usually because of peer pressure, but sometimes someone will give an explanation that sounds correct since they back it up with a scientific explanation." Another student described "...the groups I work in,.. we'll all go over the exam. If we all have answer $\mathrm{A}$, then it must be A. But the only time you'll hear discussion is when we all have random answers, and none of us know which one is right. That is when you'll start pulling out the book...." Strategies described by students ranged from superficial to deep. Some review the exam questions and arrive at their answers from explanations that simply "sound scientific". Others arrive at their answers by a majority vote, similar to the oral polling that occurred in class. On the other hand, one student's group “... [went] over each question, and it's never just the answer is A, it's always: well, no I disagree, why is it A?" This last description corresponds to the mini-debates to arrive at consensus that we observed in some class group discussions.

Summative Evaluations - Additional evidence for improved student learning comes from summative evaluations by students. Despite anecdotal reports that the introduction of student-active teaching methods in college courses often caused a decrease in the overall rating of the course by students, this did not happen. Responses to the question "This course was..." was in the same range as previous for the instructors (Figure 6). Of greater significance, questions on the evaluation about the interest in the topic and the interest in teaching showed measurable increases. The students recognized that the teaching approaches used were positive factors and acknowledged that they had benefited from the pedagogy.

On the survey after the Fall, 1997 course, we added specific questions to the evaluation asking about the impact of the teaching methods being used. To the statement "the use of small group activities in class increased the amount that I learned in this course", $85 \%$ of the students indicated that they agreed. The statement was strongly agreed with by $46 \%$ of the students (Figure 7). In addition, $63 \%$ of those surveyed agreed that the use of small group activities in class increased their interest in the course, and $88 \%$ of 237 oceanography students believed that two stage cooperative exams increased the amount they learned in the course.

Written comments by students on the summative evaluations support this assessment. Although there 


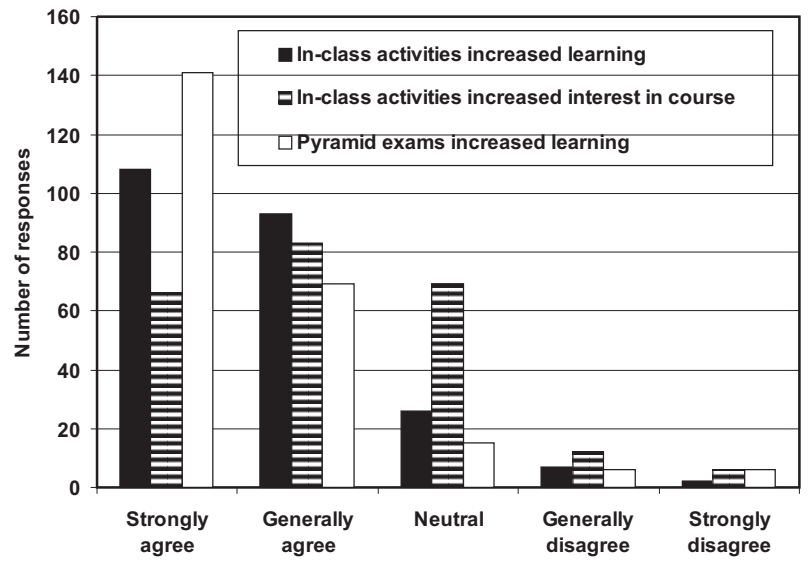

Figure 7. Student responses to questions on the summative evaluation about the effectiveness of the in-class exercises and the two-stage cooperative exams (pyramid exams).

were a few negative comments about the group in-class activities, the prevailing attitudes are summarized in the following extracts:

"I liked the interactiveness (i.e. 'pair share')...The pyramid exams were also a good idea."

"There is class time allowed to discuss problems with other classmates...I feel I learn more that way."

"The format for the exams helped me learn more.."

"I like the pyramid testing. It helps to better understand and put to use your knowledge of the material."

"The pyramid exams are very helpful to learning more."

“Group discussions...[are]...less boring and you learn more than just having someone talk to you for an hour."

"I like the "think-pair-share" technique because it allows us to become more involved in discussions."

"It's hard not to learn in this class."

"The test format is terrific - who would think you could learn something from taking a test?"

Student Interest in Science - In a separate survey conducted independently for the STEMTEC project, students were asked to rate their overall interest in science on the scale below:

\section{Strong Dislike \\ 2 Dislike \\ 3 Neutral \\ 4 Some Interest \\ 5 Strong Interest}

This question was asked both at the beginning and end of the course. The start-semester test mean was $3.3(n=345)$ on this scale, while the end-semester t-test mean was 3.6

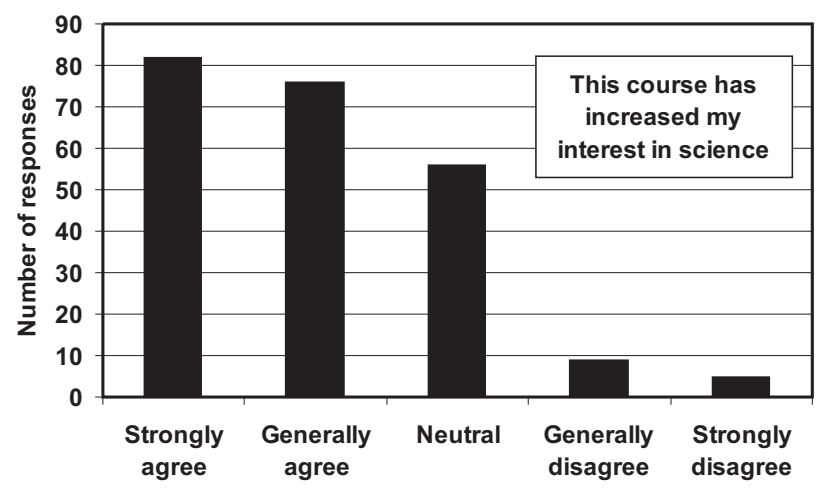

Figure 8. Student response to a question on the summative evaluation concerning the impact of the course on their interest in science.

$(n=312)$. This difference was significant at the $p=.05$ level using an unpaired t-test, two-tailed.

In the twelfth week of the course, a student commented that he now believed strongly that it's not the material you're EXPOSED TO in lecture that counts, it's the material you LEARN. He had taken another science course at the univerity and said that the present oceanography course was "really different" and that the small group activities are very important because "in other classes people may go to class and take notes, but they're not really into it - in this class people really listen because they've gotten INTERESTED in the subject." This kind of comment led us to see whether we could confirm the survey finding above by using a post course indicator. In a second survey, students were asked the question in Figure 8 at the end of the course. The graph shows that for $69 \%$ of these students, this course increased their general interest in science. The significance of this result is heightened by the fact that this is a course meeting general education requirements taken by many students who are, at best, skeptical about science.

\section{DISCUSSION}

Evidence points to a measurable and statistically significant increase in student learning and interest in this course that stems from the changes introduced in the teaching and assessment methods. It is more difficult to single out those techniques that have had the greatest impact. Certainly the increased attendance in itself has a direct connection with better performance on the final exam, since courses provide a necessary structure for efficient learning. We also assume that the active-learning strategies used in this course helped students retain what they learned, but can we examine this more closely?

One approach is to look at the distribution of numerical scores received by the students to see how these changed when the cooperative part of the exams and the in-class exercises are included. When we compare the exam performance of the Spring, 1996 class with that of the solo portion of the 1998 class, we see a similar histo- 
a) Exam Comparisons 1996 vs. 1998

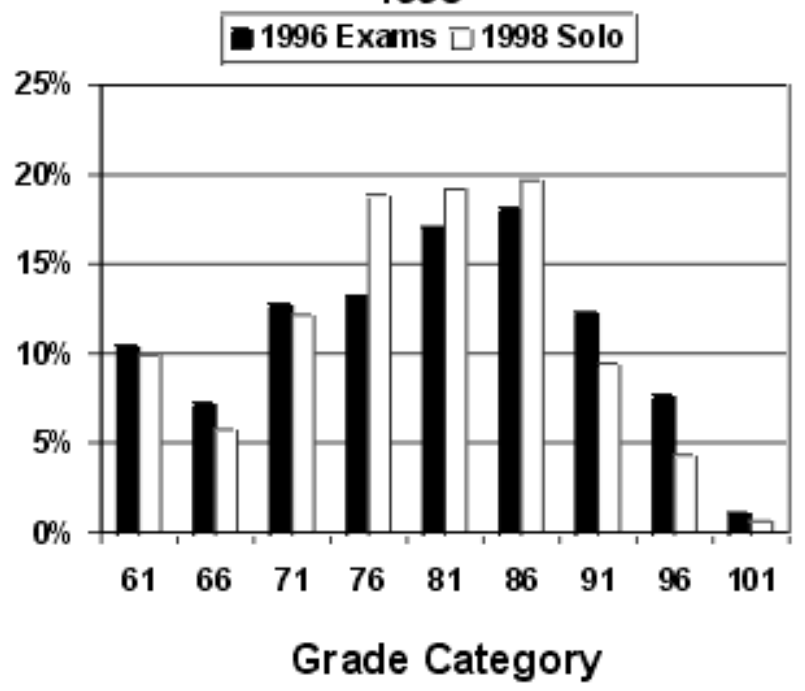

b) 1998 Grade Distribution

$\square$ Solo Only wWith Group EWith Exercises

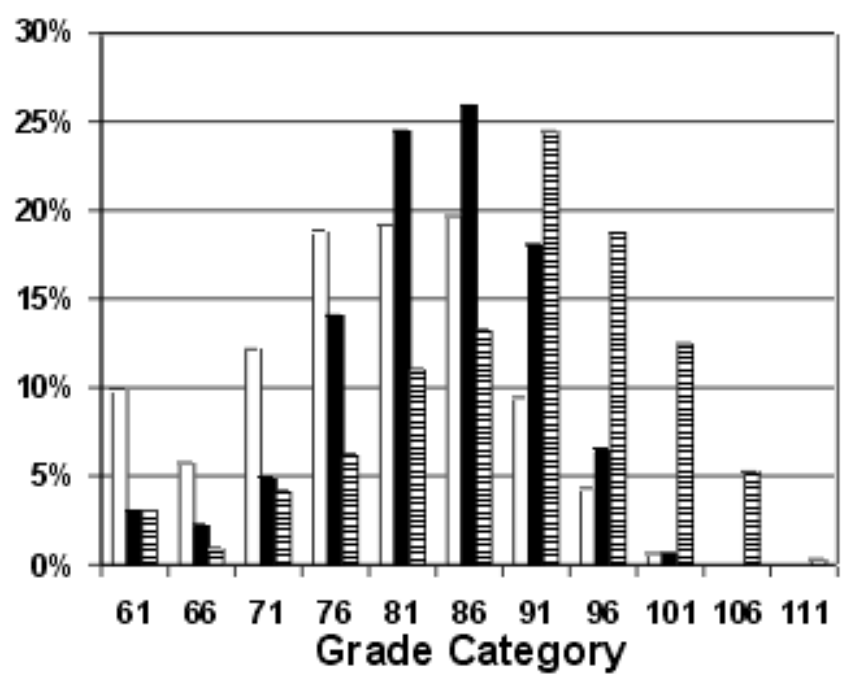

Figure 9. a) Comparisons of grade distributions for the Spring, 1996 and Fall, 1998 (Full STEMTEC) semester. b) Effects of cooperative exams and in-class exercises on grade distributions during Fall, 1998 semester.

gram of scores (Figure 9). In general, there are fewer students at the bottom rungs of the ladder, corresponding to grades of " $\mathrm{F}$ " and " $\mathrm{D}$ ", in the 1998 class $(115 / 650=18 \%$ in $1996,76 / 625=12 \%$ in 1998), which indicates that the teaching methods may be helping those students with the greatest academic difficulty. Adding the cooperative component to the exams does not change the grade distribution dramatically. Although the number of students in the lowest two categories drops to $33 / 625=5 \%$, it does not produce an unusual increase in the numbers doing very well. In essence, adding a cooperative component does not promote grade inflation, and provides a psychological boost to students who are struggling in the course.

The in-class exercises change the picture more dramatically, pushing the modal numerical scores from 81 and 86 after the exams to 91 and 96 after the exercises were factored in (Figure 9). This was a source of grade inflation, but only because we were too generous in allowing "extra credit" for more than the required number of exercises. In 1998, 12 exercises done correctly yielded 24 points, which was full credit. However, there were a total of 16 exercises completed during the semester, and all exercises above 12 were added to the final score. In the future, we will limit the total extra credit received to one or two points maximum and this should correct the grade anomaly.

The implementation of these techniques in a class of this magnitude is not without problems. In the case of the cooperative learning aspects, one issue is what we call the "bump-on-a-log" syndrome. There are some students who do not engage in consultation or collaboration during the think-pair-share exercises, but rather sit passively and appear as if they would much rather be elsewhere. These students may prefer the anonymity of the lecture hall, and they simply do not want to become engaged during class time. The reasons for this are unclear: laziness, shyness, being ill-prepared to discuss the subject with their peers or an "all-nighter" for another course may contribute to the problem, which may make an interesting research project in itself.

A related phenomenon is the reluctance to express a written conclusion or statement on the in-class exercises until the end of the process. This is a far more widespread characteristic. We feel that this stems largely from attitudes instilled by the students' earlier experiences in science education, specifically, that there is a correct answer and they do not want to be wrong. They do not have confidence in their own reasoning or deductive skills, so they wait until we enter "share" mode before filling out the response sheet. We need to do more to encourage the students to put their own thoughts down so that they can be thinking more actively during the discussion phase.

More difficult are the "active resisters." These are relatively few in number, and they are often "alternative" students who do not mix easily with undergraduates of a more traditional age. These students prefer to receive information directly from the professor rather than collaborate on answers with other class members. These students also do not discuss their answers with others during the group parts of the exams. We are sympathetic to their opinions, but they miss the tangible benefit of processing the information by discussing it with their peers.

Management of the class is also an ongoing issue. It takes continuous effort and monitoring to keep students on task, and groups in the corners of the lecture hall or in the middle of a row of seats receive no faculty oversight. The only mechanism we have to ensure they discuss the topic is the response sheet, but this suffers from the "wait-until-the-end" phenomenon discussed previously. 
Perhaps one solution to this is to have advanced undergraduates or geology majors act as subordinate monitors to help move discussion along where needed.

Assessing the reporting sheets is still very rudimentary, with grades of " 0 " "1" and " 2 " assigned based on the quality and depth of the responses. We select a limited number of these for more in-depth commentary, but with 10,000 pieces of paper turned in during the semester, it is not possible to give these more than a cursory look. A more thorough review would help evaluate the effectiveness of these exercises in improving student understanding of the subject. A related matter is providing students with sufficient feedback on their performance. They can gather some information from their numerical scores, but direct commentary on their responses should improve their own understanding of the concepts and processes more vigorously.

We are incorporating more technology into the course, and this may alleviate some of the problems. Specifically, the lecture portions of are being put into presentation software that incorporates diagrams and questions that help guide the students through the in-class exercises. The summative evaluations from Fall, 1998 consistently mentioned the positive aspects of the computer-assisted presentations. In addition, we have added an on-line web-based learning $(\mathrm{OWL})$ system to the course that requires students to answer questions and solve problems as the course proceeds. This gives them some additional constructive feedback on their understanding of the basic course concepts. Future plans include replacing the paper response sheets with an electronic personal response system such as, and having a secure, password-protected server that will enable students to access their grades and assess their status at any time. These changes will simplify the management and may improve the educational benefits that the students receive, but they only build upon the positive results that have been achieved by making this course student-active and cooperative.

\section{CONCLUSIONS}

Student-active teaching enhances the learning environment in large classes, and it is not difficult to implement. Using think-pair-share techniques and informal groups stimulate student interest in and understanding of the subject matter. Structuring these activities around in-class exercises helps provide a consistency to their implementation, and increases the attendance a nd participation during class. The two-stage cooperative exam, in addition to giving a morale boost to students, provides an opportunity for them to discuss and uncover the reasoning behind exam questions. Analysis of results from the exams, course evaluations and student interviews indicates that the long-term retention of information and the ability to process data are enhanced by these techniques. Lectures have their place as an efficient way of summarizing important concepts, but inquiry by the students themselves is a necessary part of the class if students are to appreciate the techniques of scientific investigation. It appears possi- ble, even in the case of a large enrollment science course, to implement cooperative learning and exam strategies that make learning a more interactive process and that have a positive effect on exam scores. We are particularly encouraged that a large majority of students in this general education course reported that the course had also increased their interest in science.

\section{ACKNOWLEDGMENTS}

The modifications to the oceanography course and its evaluation were supported by the STEMTEC project, a NSF "Collaborative for Excellence in Teacher Preparation" (DUE9653966). We appreciate the cooperation of our colleagues Laurie Brown and Julie Brigham-Grette, who have helped implement these changes. Elizabeth Connors, Fritz Stahr and the associate editors of the journal provided constructive comments, which were helpful in the revision of the manuscript.

\section{REFERENCES}

Cohen, D. and Henle, J., 1995, The pyramid exam: UME Trends, no. July, p. 2,15.

D’Avanzo, C. and McNeal, A. P., 1997, Research for all students: structuring investigation into first-year courses: McNeal, Ann P., and D'Avanzo, Charlene, Editors, Student-Active Science: Models of Innovation in College Science Teaching: Fort Worth, TX, Saunders, p. 279-299.

Frederick, P., 1987, Student involvement: active learning in large classes Weimer, M. G. (editor), Teaching Large Classes Well: San Francisco, CA, Jossy-Bass, p. 45-56.

George, M., 1996, Shaping the Future: New Expectations for Undergraduate Education in Science, Mathematics, Engineering and Technology: Arlington, VA, National Science Foundation, 76 pages.

Leckie, M. R. and Yuretich, R., 2000, Investigating the Ocean: An interactive guide to the science of oceanography: New York, McGraw-Hill, 189 p.

Merriam, R. W., 1986, Academic research vs. the liberal arts: Journal of College Science Teaching, v. 16, p. 105-109.

NRC (National Research Council), 1996, National Science Education Standards: Washington, DC, National Academy Press. 262 p.

Seymour, E. M. and Hewitt, N. M., 1997, Talking about Leaving: Why undergraduates leave the sciences: Boulder, CO, Westview. 429 p.

Springer, L., Stanne, M. E., and Donovan, S., 1997, Effects of cooperative learning on undergraduates in science, mathematics, engineering and technology: a meta-analysis: Madison, WI, National Institute for Science Education, 40 p. 